\title{
ANALISIS SISTEM PERENCANAAN TRANSPORTASI UMUM DENGAN MENGGUNAKAN MODEL VOLUME CAPACITY RATIO
}

\author{
Yusup Jauhari Shandi
}

\author{
Sekolah Tinggi Manajemen Informatika dan Komputer LIKMI \\ Jl. Ir. H. Juanda Bandung 40132 \\ E-mail : ujshandi@gmail.com
}

\begin{abstract}
ABSTRAK
Kota-kota besar di Indonesia saat ini menghadapi banyak permasalahan serius, salah satunya adalah masalah transportasi. Kemacetan seolah-olah menjadi ritual yang harus dilalui masyarakat yang beraktifitas di kota tersebut. Gelombang urbanisasi terutama yang bersumber dari wilayah yang berbatasan langsung dengan kota tersebut menjadi salah satu penyumbang masalah transportasi di wilayah kota besar. Perencanaan serta pengambilan langkah-langkah yang yang harus diambil terkait permasalahan ini harus didukung dengan sistem. Dengan kehadiran sebuah sistem diharapkan proses perencanaan sarana lalu lintas, serta pengelolaanya menjadi lebih efektif dan efisien. Terutama kebijakan mengenai transportasi umum.
\end{abstract}

Kata Kunci : transportasi, volume kapacity ratio, kemacetan.

\section{PENDAHULUAN}

Transportasi merupakan salah satu unsur yang terpenting di dalam perekonomian, karena transportasi sangat erat kaitannya dengan aktifitas masyarakat khususnya masyarakat di perkotaan. Tanpa adanya transportasi maka aktifitas atau kegiatan masyarakat menjadi terganggu. Angkutan umum adalah salah satu jenis sarana transportasi yang paling banyak digunakan oleh masyarakat sehari - hari, karena biaya yang relatif murah dan terjangkau oleh sebagian besar kalangan masyarakat. Untuk wilayah yang memiliki predikat Kota Besar, angkutan umum berbasis jalan dan berbasis rel dituntut untuk meningkatkan pelayanan dalam rangka mengakomodir kebutuhan perjalanan penumpang dan barang.

Dalam rangka penyelenggaraan angkutan umum yang nyaman dan aman bagi penumpang perlu ditunjang dengan adanya kondisi prasarana yang memadai. Fasilitas dan Infrastrukur transportasi yang kurang menjadi salah satu penyebab utama terjadinya kemacetan tersebut.

Oleh karena itu, agar berbagai persoalan yang timbul dapat diidentifikasi dengan teknologi sistem informasi geografis yang menyajikan gambaran informasi sarana dan prasarana dan jalur untuk pembuatan peta digital dan hasil akhirnya akan membuat suatu tampilan aplikatif tentang gambaran potensi transportasi di sebuah kota. Sehingga dengan pemanfaatan peta interaktif dalam bentuk digital ini diharapkan dapat membantu pihak pengambil keputusan di wilayah kota terkait agar dapat meningkatkan kualitas pelayanan dan kenyamanan kepada masyarakat akan penggunaan sarana dan prasarana transportasi di wilayahnya. 


\section{URBANISASI}

Daya tarik perkotaan dalam hal bisnis dan ekonomi menimbulkan banyaknya migrasi dari daerah pedesaan ke daerah perkotaan. Kegiatan ini menimbulkan infrastruktur perkotaan mengalami penurunan dikarenakan kapasitas yang ditargetkan pada awal pembangunan tidak mampu memprediksi lonjakan yang hebat arus imigrasi dari daerah ke perkotaan. Pada 2015, struktur penduduk kota dan desa menunjukkanbahwa penduduk Indonesia di perkotaan sebanyak 126,3 juta jiwa. Sedangkan dipedesaan jumlahnya lebih banyak, yakni 128,5 juta jiwa. Jumlah penduduk perkotaan ini merupakan 49,55\% dari total penduduk Indonesia. Menurut Sensus Penduduk 2010 masih sebanyak 118,3 juta jiwa sehingga terjadi peningkatan yang signifikan.

Diperkirakan setiap hari penduduk kota meningkat 15.479 orang atau 5,65 juta orang per tahun. Kementerian Dalam Negeri memperkirakan pada Tahun 2025 sebanyak $65 \%$ penduduk akan mendominasi hunian di perkotaan terutama di 16 kota besar yang ada di Indonesia. ADB (ASEAN Development Bank) memperkirakan 80\% pertumbuhan ekonomi baru di Asia berasal dari wilayah perkotaan karena posisinya sebagai pusat konsentrasi pekerja dan lapangan kerja. Bukti ini menguatkan bahwa kota juga merupakan pusat peredaran ekonomi nasional.

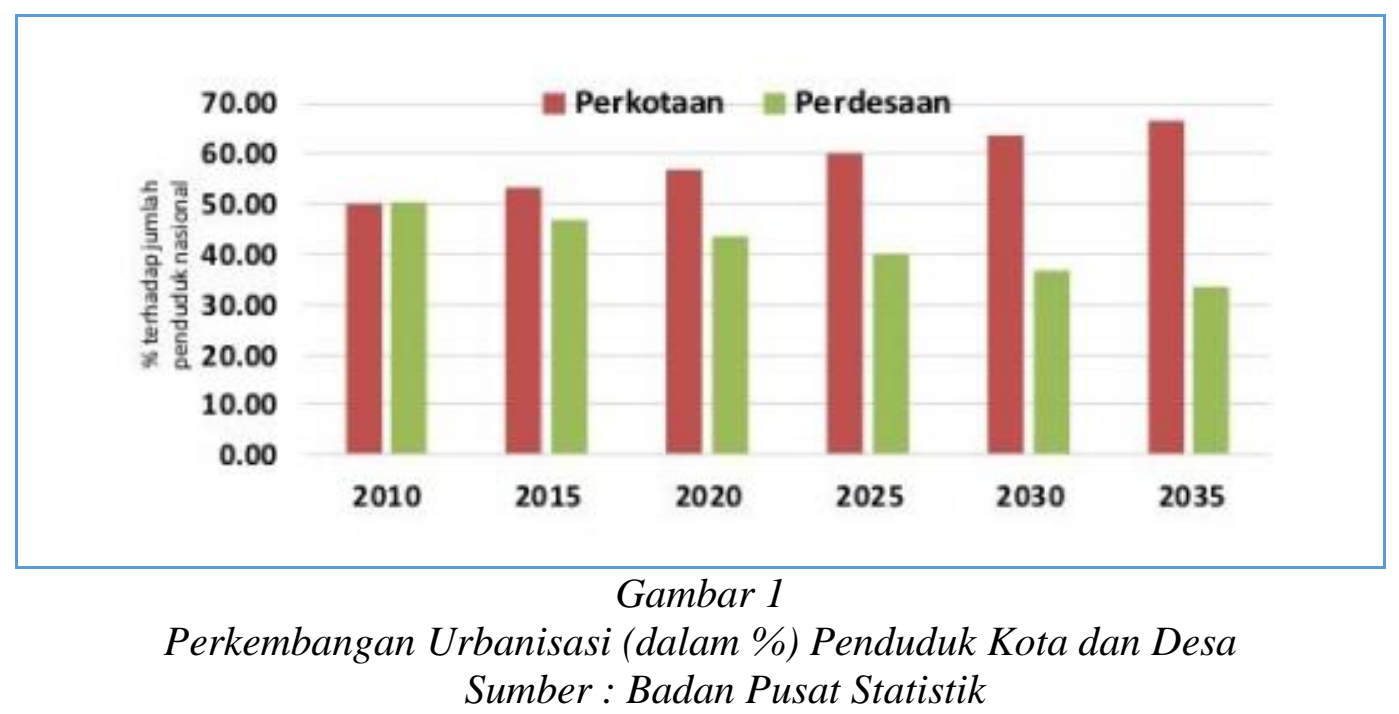

\section{AGLOMERASI}

Bertambah pentingnya peran kota mendorong tumbuhnya aglomerasi wilayah, melewati batasan administrasi. Kekuatan utama (driving force) dibalik urbanisasi yang cepat di kawasan Asia sejak dasawarsa 1980-an yang disebabkan Industrialisasi mengakibatkan pembentukan aglomerasi. Tingginya urbanisasi akan menyebabkan tingginya beban mobilitas perkotaan.

Wilayah aglomerasi perkotaan didefinisikan dalam dua pengertian, yaitu persoalan wilayah dan kependudukan. Dua pendorong tumbuhnya aglomerasi: 1) Kota umumnya menawarkan banyak kelebihan dalam bentuk produktifitas dan pendapatan lebih tinggi, teknologi baru, menarik investasi baru, pekerja terampil dan terdidik dalam jumlah yang jauh lebih banyak dibandingkan perdesaan 2) Industri cenderung menumpuk di daerah-daerah dimana kemampuan dan potensi daerah tersebut memenuhi kebutuhan mereka dan mereka mendapat manfaat karena lokasi perusahaan yang saling berdekatan. (Malecki, 1991)

Buruknya sistem angkutan umum perkotaan yang saat ini ada menjadi pemicu semakin tingginya penggunaan kendaraan pribadi. Fasilitas yang jauh dari kata nyaman dan aman, serta ketidakjelasan jadwal kedatangan dan pemberangkatan 
berimbas pada masyarakat lebih memilih menggunakan kendaraan pribadi. Pertumbuhan kendaraan bermotor yang sangat tinggi (rata-rata 12\% per tahun) telah menimbulkan permasalahan yang sangat serius. Hal ini berdasarkan ketersediaan prasarana yang berupa penambahan infrastruktur jalan relatif kecil (rata-rata 0,01\% per tahun). Beban jalan semakin padat yang ditandai dengan $\mathrm{V} / \mathrm{C}$ ratio yang sudah mendekati 0,8. Kecepatan saat berkendaraan yang relatif rendah dan waktu tempuh yang semakin lama merupakan indikasi yang dapat dirasakan para pengguna jalan.

\section{ANALISIS VOLUME, CAPACITY AND RATIO (VCR)}

Analisis VCR merupakan analisis yang dilakukan dengan cara membandingkan antara volume kendaraan dan kapasitas. Dalam menilai kinerja jaringan jalan dengan indikator penilaian menggunakanrasio kapasitas dan volume atau VCR, langkah awal adalah mengidentifikasi ruasjalan yang akan dinilai. Identifikasi dilakukan dengan menginventarisir ruas jalandan kemudian melihat koridor pengembangan transportasi yang ada, baik eksisting maupunrencana pengembangan,sehingga kemudian ruas jalan tersebut lebih didalamiterkait penilaian kinerjanya.

Tahapan awal setelah teridentifikasinya ruas jaringan jalan, yaitu melakukan penilaian kinerja jaringan jalan tersebut berdasarkan kinerjanya yaitu dengan menilai rasio kapasitas dan volume kendaraan di ruas jalan yang bersangkutan. Nilai rasio kapasitas dan volume kendaraan didapatkan dari data IRMS Kementerian PU, hasil dari identifikasi data rasio dan volume kendaraan.

Proyeksi pertumbuhan volume lalu lintas kendaraan dapat dihitung dengan rumus :

$$
V T P=V L x \quad \boldsymbol{I}(1+P K) \AA(T P-T S)
$$

Keterangan :

VTP $=$ Volume di Tahun yang diproyeksikan

$\mathrm{VL}=$ Volume Lalu lintas saat ini

$\mathrm{PK}=$ Pertumbuhan Kendaraan $(\%)$

TP $=$ Tahun Proyeksi

TS = Tahun perhitungan volume Lalu lintas awal (VL).

Untuk simulasi perhitungan Satuan Mobil Penumpang(SMP) didapatkan dari :

SMP $=$ Volume Lalu Lintas $x$ Equivalen Mobil Penumpang

Keterangan :

SMP = Satuan Mobil Penumpang

Kapasitas Jalan dihitung dari :

\section{C = Jumlah Lajur $x$ Co $x$ FCw FCsp $x$ FCsf $x$ FCcs}

Keterangan :

$\mathrm{C}=$ kapasitas ruas jalan $(\mathrm{SMP} / \mathrm{Jam})$

$\mathrm{Co}=$ kapasitas dasar

$\mathrm{FCw}=$ faktor penyesuaian kapasitas untuk lebar jalur lalu-lintas

$\mathrm{FCsp}=$ faktor penyesuaian kapasitas untuk pemisahan arah

FCsf $=$ faktor penyesuaian kapasitas untuk hambatan samping

$\mathrm{FCcs}=$ faktor penyesuaian kapasitas untuk ukuran kota.

Dengan pemodelan akhir VCR dihitung dari :

$$
V C R=\frac{S M P}{C}
$$

Untuk perhitungan nilai perubahan volume kapasitas jalan setelah penambahan moda :

$$
\begin{aligned}
& \text { VTPlv }=\left(V L x(1+P K)^{T P-T S}\right)-\min L V \\
& \text { VTPmc }=\left(V L x(1+P K)^{T P-T S}\right)-\min M C
\end{aligned}
$$

Keterangan : 
Min LV = Jumlah kendaraan ringan minimum yang berpindah moda

Min MC = Jumlah motor minimum yang berpindah moda.

Perhitungan VCR dan LHR menggunakan beberapa variabel masukan sebagai berikut :

\begin{tabular}{|l|l|}
\hline \multicolumn{1}{|c|}{ Variabel } & \multicolumn{1}{c|}{ Deskripsi } \\
\hline Jumlah moda & $\begin{array}{l}\text { Jumlah moda transportasi umum existing dan proyeksi } \\
\text { penambahan moda pada tahun-tahun mendatang. }\end{array}$ \\
\hline Tingkat okupansi & Tingkat persentase okupansi moda transportasi umum. \\
\hline Kapasitas moda & Jumlah kapasitas angkut moda transportasi umum \\
\hline Total moda terisi & $\begin{array}{l}\text { Jumlah moda terisi yang diperoleh dari : } \\
\text { Total moda terisi = jumlah moda } * \text { tingkat } \text { okupansi } \\
\text { kapasitasmoda. }\end{array}$ \\
\hline Lebar jalan & Lebar ukuran jalan yang dinyatakan dalam meter. \\
\hline Pertumbuhan kendaraan & Tingkat persentase pertumbuhan jalan. \\
\hline Lajur jalan & Jumlah lajur dari setiap jalan yang dihitung. \\
\hline
\end{tabular}

Hasil dari identifikasi VCR dan penilaian pembobotan dengan skoring untuk jaringan jalan pada koridor di wilayah sample disampaikan dalam contoh Tabel 1 dan Tabel 2.

\begin{tabular}{|c|c|c|}
\hline No. & Ruas Jalan & Panjang (KM) \\
\hline 1 & Jalan A & 4,77 \\
\hline 2 & Jalan B & 7,67 \\
\hline 3 & Jalan C & 1,12 \\
\hline 4 & Jalan D & 0,81 \\
\hline
\end{tabular}

Tabel 1. Contoh Data Panjang Ruas Jalan

\begin{tabular}{|c|c|c|c|}
\hline No. & Ruas Jalan & VCR & LOS \\
\hline 1 & Jalan A & 1,00 & F \\
\hline 2 & Jalan B & 0,91 & E \\
\hline 3 & Jalan C & 1,00 & F \\
\hline 4 & Jalan D & 0,86 & D \\
\hline
\end{tabular}

Tabel 2. Contoh hasil penilaian VCR untuk ruas jaringan

Selanjutnya untuk menilai kinerja ruas jalan yang akan dipilih menjadi locus studi ini yaitu dilakukan penilaian kinerja jaringan jalan tersebut berdasarkan kinerja kecepatan rata-rata kendaraan pada ruas jalan tersebut. Nilai kecepatan rata-rata kendaraan didapatkan dari data IRMS Kementerian PU. Nilai kecepatan rata-rata yang kemudian diterjemahkan kepada Level of Servive (LOS) jalan berdasarkan kecepatan rata-rata (AV Speed), maka selanjutnya dilakukan penilaian dengan skoring. Sistem skoring yang diberikan adalah sebagai berikut :

LOS AV Speed A $:$ skor penilaian $=1$
LOS AV Speed B $:$ skor penilaian $=2$
LOS AV Speed C $:$ skor penilaian $=3$
LOS AV Speed D $:$ skor penilaian $=4$
LOS AV Speed E $:$ skor penilaian $=5$
LOS AV Speed F $:$ skor penilaian $=6$


Hasil dari identifikasi kecepatan rata-rata dan penilaian pembobotan dengan skoring untuk jaringan jalan pada wilayah tersebut disampaikan dalam Tabel 3.

\begin{tabular}{|c|c|c|c|c|}
\hline No. & Ruas Jalan & AV Speed & LOS & Skor \\
\hline 1 & Jalan A & 16,15 & F & 6 \\
\hline 2 & Jalan B & 19,46 & F & 6 \\
\hline 3 & Jalan C & 27,61 & D & 4 \\
\hline 4 & Jalan D & 29,53 & D & 4 \\
\hline
\end{tabular}

Tabel 3. Penilaian kinerja berdasarkan kecepatan rata-rata ruas jaringan jalan

\section{ANALISA DAN PERANCANGAN SISTEM}

Aplikasi yang dirancang ini output akhirnya berupa peta yang diber garis (line) dengan warna yang menggambarkan data atau nilai VCR nya. Berikut hasil analisis yang dituangkan dalam diagram UML :

\section{USE CASE DIAGRAM}

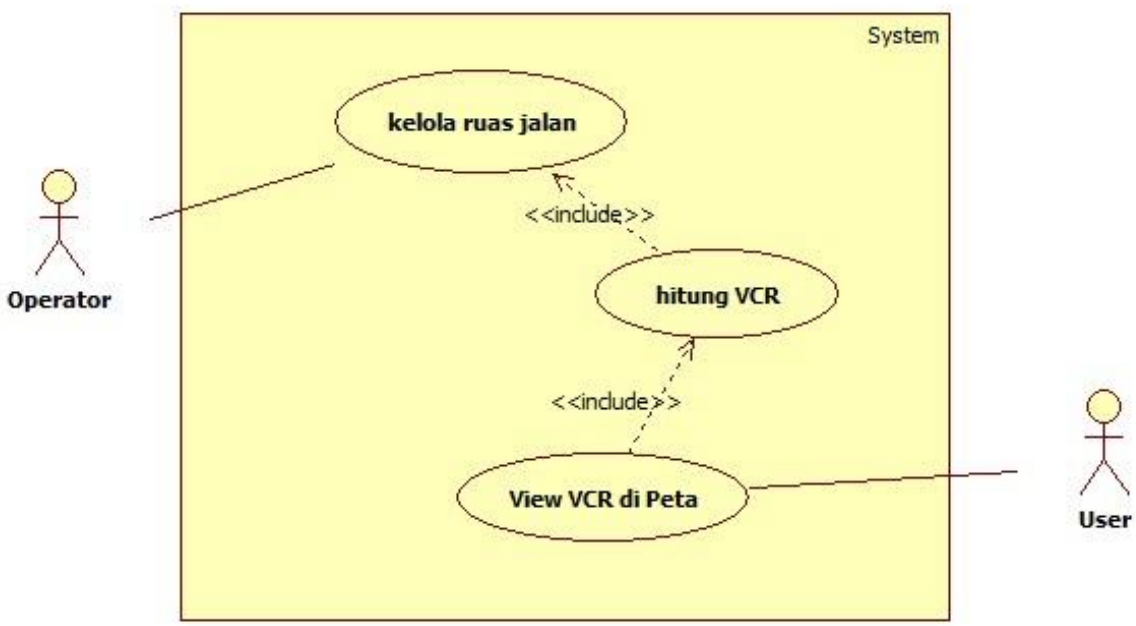

\section{CLASS DIAGRAM}

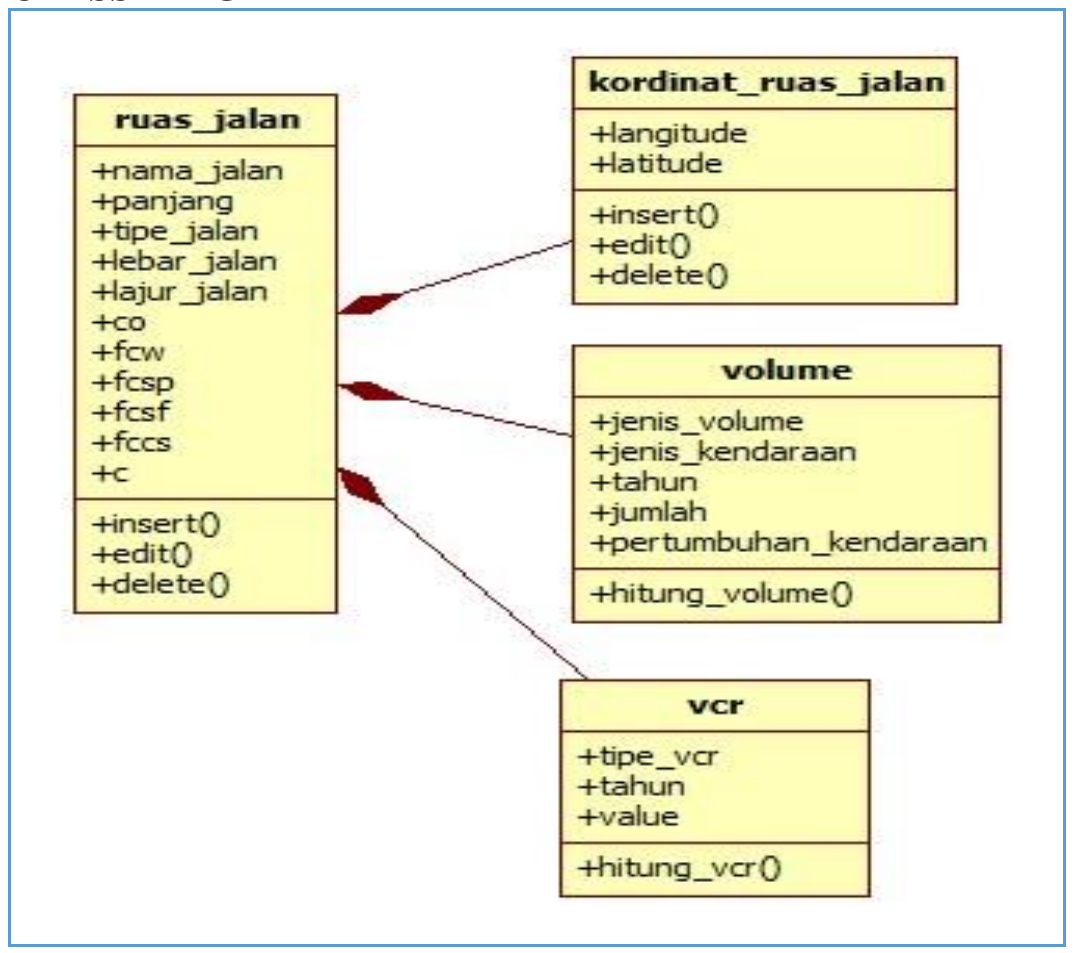




\section{KESIMPULAN}

Aplikasi ini nantinya bisa dimanfaatkan oleh dinas terkait terutama untuk kota besar. Dengan adanya aplikasi ini diharapkan dinas terkait bisa membuat kebijakan yang tepat dalam hal mengurangi permasalahan kemacetan yang terjadi di sebuah wilayah. Kebijakan yang nantinya bisa terbantu dengan sistem ini khususnya yang berkaitan dengan kebijakn transportasi umum.Penelitian selanjutnya bisa melengkapi dengan objek kasus nyata (bukan sampel) dan melengkapinya dengan prototipe dari aplikasi yang sudah jadi.

\section{DAFTAR PUSTAKA}

[1]. Departemen Pekerjaan Umum, Manual Kapasitas Jalan Indonesia, Jakarta, Ditjen Bina Marga, 1997.

[2]. Malecki, Technology and Economic Development : the Dynamics of Local, Regional, and National Change. NewYork : John Wiley \& Sonc, Inc. 1991 